\title{
Clinical characteristics of patients with motor disability due to conversion disorder: a prospective control group study
}

\author{
Michael Binzer, Peter M Andersen, Gunnar Kullgren
}

\begin{abstract}
Objectives-Previous studies have suggested associations between conversion and many different clinical characteristics. This study investigates these findings in a prospective design including a control group.
\end{abstract}

Methods-Thirty consecutive patients with a recent onset of motor disability due to a conversion disorder were compared with a control group of patients with corresponding motor symptoms due to a definite organic lesion. Both groups had a similar duration of symptoms and a comparable age and sex profile and were assessed on a prospective basis. Background information about previous somatic and psychiatric disease was collected and all patients were assessed by means of a structured clinical interview linked to the diagnostic system DSM III-R, the Hamilton rating depression scale, and a special life events inventory. Results-The conversion group had a higher degree of psychopathology with $33 \%$ of the patients fulfilling the criteria for psychiatric syndromes according to DSM-III-R axis I, whereas $50 \%$ had axis II personality disorders compared with $10 \%$ and $17 \%$ respectively in the control group. Conversion patients also had significantly higher scores according to the Hamilton rating depression scale. Although patients with known neurological disease were not included in the conversion group, a concomitant somatic disorder was found in $33 \%$ of the patients and $50 \%$ complained of benign pain. The educational background in conversion patients was poor with only $13 \%$ having dropped out of high school compared with $67 \%$ in the control group. Self reported global assessment of functioning according to the axis V on DSM IV was significantly lower in conversion patients, who also registered significantly more negative life events before the onset of symptoms than controls. Logistic regression analysis showed that low education, presence of a personality disorder, and high Hamilton depression score were significantly associated with conversion disorder.

Conclusion-The importance of several previously reported predisposing and precipitating factors in conversion disorder is confirmed. The results support the notion that conversion should be treated as a symptom rather than a diagnosis and that efforts should be made in diagnosing and treating possible underlying somatic and psychiatric conditions.

\section{(f Neurol Neurosurg Psychiatry 1997;63:83-88)}

Keywords: conversion disorder; motor symptoms; psychogenic paralysis

Neurologists are often confronted with patients presenting neurological symptoms without an organic cause. Motor disability is a common symptom but abnormal movements, hypoaesthesia, aphonia, seizures, blindness, and deafness are other manifestations of conversion symptoms often seen in a neurological department. According to the DSM IV criteria ${ }^{1}$ for conversion disorder, subconscious psychological factors are judged to be associated with the symptom because of a temporal relation between a psychosocial stressor or psychological conflict, and initiation or exacerbation of a symptom. The diagnosis thus carries a certain aetiological implication and psychodynamic mechanisms are still widely suggested to be associated with conversion. The pathophysiological pathways involved in the "would be" conversion of emotional tension into various somatic pathways are, however, completely unknown and most authorities tend to employ a multidimensional approach to the understanding of conversion in which there are both separate and simultaneous biological, psychodynamic, sociocultural, and behavioural explanations. $^{2-7}$ Proposals for terminology and classification are almost exclusively dealt with by psychiatrists even though most patients are treated by neurologists. Broader clinical needs thus may not always be taken into account.

Despite major changes in inclusion criteria during the past few decades with a trend towards less emphasis on psychogenesis, the validity of the conversion disorder diagnosis remains unestablished, and it has been suggested that conversion should be evaluated as a symptom rather than as a primary diagnosis. ${ }^{278}$ In many previous studies diagnostic boundaries are ill defined, and there is a general tendency to also include patients with idiopathic pain or other somatoform disorders. ${ }^{9-13}$ In DSM IV the conversion symptom is specified as motor, sensory, convulsion, or mixed, and in the International Classification of Psychiatric Disorders (ICD revised form 6 February

1997

Accepted 10 February 1997 
$10)^{14}$ these different clinical manifestations of conversion are actually treated as separate disorders under the general title of dissociative disorders.

With or without aetiological relevance, previous studies have suggested associations between conversion and many different clinical characteristics. Female sex ${ }^{12}{ }^{13}$ position within siblings, ${ }^{15} 16$ low socioeconomic status, ${ }^{17} 18$ depression, ${ }^{5} 1213$ personality disorders, ${ }^{19}{ }^{20}$ and emotional stress ${ }^{18}{ }^{21}$ have all been proposed to be associated with conversion. The previous studies are, however, to a large extent hampered by somewhat unsystematic diagnostic procedures as well as poorly defined sample selection, and findings need replication in studies with more homogenous and representative samples and with more reliable diagnostic assessments. ${ }^{7}$

The overall purpose of the present study is to investigate findings suggested in previous studies in a thorough prospective design including a control group. Focus is put on current and past psychopathology and life events, and their association with motor conversion disorder. Only patients with motor conversion symptoms are included and there are several reasons for this restriction. Motor symptoms are dramatic enough to bring the patients early to hospital enabling us to include patients with a short duration of symptoms. Motor symptoms pose less differential diagnostic problems allowing for a more homogeneous sample and they are very likely to bring the patient to the neurological department, making the sample more representative.

\section{Methods}

PATIENTS

During a period of 24 months at the neurological department in Umeå 18 consecutive inpatients with motor disability due to conversion disorder and a duration of symptoms of less than three months were assessed on a prospective basis. A further 12 consecutive inpatients were recruited from the neurological section at the Department of General Medicine of the county hospital of Kalmar during a 22 month period. Both hospitals have primary catchment areas of about 130000 patients. Of the total of 30 patients, 20 were referred directly to neurological services and four were referred from other departments in the same hospital; the remaining six patients came from other hospitals for a second opinion. None of the patients refused to participate in the study.

A further five patients with the diagnosis of motor conversion disorder, all refugees from foreign countries, had to be omitted due to language problems. Patients with tremor, odd looking gait disturbances, and known neurological disease were also omitted due to the risk of including patients in whom the symptoms might have an organic cause.

The possibility of a somatic cause to the patients' symptoms was carefully excluded by means of clinical and relevant radiological, neurophysiological, and biochemical investigations.
At the same two investigation sites, 30 control patients were recruited among consecutively admitted patients with a definite organic lesion in the nervous system resulting in a rapid onset of motor symptoms. Index patients and controls were recruited during roughly the same time span, and because we overwhelmingly expected younger conversion patients, we decided to exclude patients older than 65 in the control group. Again, only patients with a symptom duration of less than three months were included, and patients with previous motor symptoms due to neurological disease - that is, multiple sclerosis or strokewere excluded. The control group consisted of four patients with traumatic myelopathy, four with myelitis, three with Guillain Barré syndrome, nine with stroke, and 10 with a first relapse of demyelinating disease with motor symptoms. In Umeå, responsibility for stroke management is shared by the Departments of Medicine and Neurology, and patients admitted to the Department of Medicine were not considered for participation in the study. None of the patients in the control group refused to participate. The study was approved by the research ethics committee of Umeå University, Sweden.

\section{DESIGN AND INSTRUMENTS}

Background information about previous somatic and psychiatric disease in patients as well as in relatives was collected by means of a standardised interview and by review of earlier records. All patients underwent clinical and paraclinical investigations looking for possible concomitant somatic illness. Psychiatric diagnoses were assessed by means of SCID-I for clinical syndromes and SCID-II for personality disorders, which are structured clinical interviews linked to the diagnostic system DSM III-R..$^{22}{ }^{23}$ At a later stage all patients in the study were reassessed according to DSM IV criteria and the correct diagnosis was confirmed in all cases. Patients scored their level of psychological, social, and occupational functioning during the past year according to the axis V on DSM IV by means of a recently validated self report version of the global assessment of functioning score. ${ }^{24}$ The degree of depressive symptoms was assessed by means of the Hamilton psychiatric rating depression scale. $^{25}$

The occurrence of life events 12 to four months before and within three months of the onset of the symptom were assessed by the use of a five item life events inventory constructed as a guideline for semistructured interviews. ${ }^{26}$ Life events were sorted into events concerning (1) work, (2) family life, (3) economy, (4) disease or death among friends and relatives, and (5) events related to the patient's own health. It was also recorded whether the life event was expected or not, positive or negative, easy or difficult to adjust to, and whether or not it was controllable.

STATISTICS

Statistical analyses were made by means of Fisher's exact test and Student's $t$ test. A logis- 
Table 1 Background factors

\begin{tabular}{|c|c|c|c|}
\hline & $\begin{array}{l}\text { Conversion } \\
\text { group } \\
(n=30)\end{array}$ & $\begin{array}{l}\text { Control } \\
\text { group }(n=30)\end{array}$ & Statistics \\
\hline Mean age (range) & $38.8(18-4)$ & $33.8(19-64)$ & $t=1.53, \mathrm{NS}$ \\
\hline Female/male & $18 / 12$ & $21 / 9$ & Fisher's NS \\
\hline Married & 19 & 20 & Fisher's NS \\
\hline $\begin{array}{l}\text { Youngest sibling } \\
\text { or only child }\end{array}$ & 20 & 14 & Fisher's NS \\
\hline $\begin{array}{l}\text { High school } \\
\text { attendants }\end{array}$ & 3 & 12 & $\begin{array}{l}\text { Fisher's } \\
P<0.001\end{array}$ \\
\hline $\begin{array}{l}\text { University } \\
\text { graduates }\end{array}$ & 1 & 8 & $\begin{array}{l}\text { Fisher's } \\
P<0.05\end{array}$ \\
\hline
\end{tabular}

Table 2 Clinical presentation

\begin{tabular}{|c|c|c|c|}
\hline & $\begin{array}{l}\text { Conversion } \\
\text { group }(n=30)\end{array}$ & $\begin{array}{l}\text { Control } \\
\text { group } \\
(n=30)\end{array}$ & Statistics \\
\hline Monoparesis & 9 & 0 & - \\
\hline Hemiparesis & 13 & 11 & Fisher's NS \\
\hline Paraparesis & 7 & 18 & $\begin{array}{l}\text { Fisher's } \\
\mathrm{P}<0.01\end{array}$ \\
\hline Triparesis & 1 & 0 & - \\
\hline Tetraparesis & 0 & 1 & - \\
\hline $\begin{array}{l}\text { Left sided } \\
\text { symptoms }\end{array}$ & 16 & 4 & $\begin{array}{l}\text { Fisher's } \\
\mathrm{P}<0.001\end{array}$ \\
\hline $\begin{array}{l}\text { Right sided } \\
\text { symptoms }\end{array}$ & 5 & 7 & Fisher's NS \\
\hline $\begin{array}{l}\text { Moderate } \\
\text { disability }\end{array}$ & 22 & 25 & Fisher's NS \\
\hline Gross disability & 8 & 5 & Fisher's NS \\
\hline
\end{tabular}

*Twenty nine conversion patients and twenty eight control patients were right handed.

tic regression model was performed with conversion disorder as dependent variable and crucial clinical characteristics entered stepwise.

\section{Results}

When including the five patients who did not undergo assessment and at the same time excluding the six patients referred from other hospitals, the annual incidence of patients with severe motor conversion symptoms was estimated to be 4.6/100 000 in Umeå and 5.0/100 000 in Kalmar. This corresponded to $0.85 \%$ of admissions to the Neurological Department of the University Hospital in Umeå and $0.09 \%$ of admissions to the Department of Internal Medicine in Kalmar.

Both patient groups were comparable in terms of mean age, sex, and symptom duration (table 1). Twenty patients in the conversion group were found to be the only or youngest child in the family as opposed to 14 patients in the control group, and a total of 20 patients in the control group had dropped out of high school or university compared with only four patients in the conversion group (Fisher's $\mathrm{P}<0.001)$.

Table 2 shows the clinical presentation of symptoms in both groups. In the conversion group there were significantly more patients with monoparesis and with left sided symptoms but less patients with paraparesis. No significant sex differences were identified within the conversion or the control group.

Illness, psychiatric, as well as somatic, was more prevalent in the first degree relatives of the conversion patients; nine versus two (Fisher's, $\mathrm{P}<0.05$ ) and 24 versus 11 (Fisher's, $\mathrm{P}<0.01)$ respectively. Twenty one conversion patients had a history of previous hospital admission due to somatic disease compared
Table 3 Concomitant somatic and mental disorders

\begin{tabular}{|c|c|c|c|}
\hline & $\begin{array}{l}\text { Conversion } \\
\text { group } \\
(n=30)\end{array}$ & $\begin{array}{l}\text { Control } \\
\text { group } \\
(n=30)\end{array}$ & Statistics \\
\hline Somatic disorder & 10 & 4 & Fisher's NS \\
\hline Pain & 15 & 5 & $\begin{array}{l}\text { Fisher's } \\
\mathrm{P}<0.01\end{array}$ \\
\hline Major depression & 8 & 2 & $\begin{array}{l}\text { Fisher's } \\
\mathrm{P}<0.05\end{array}$ \\
\hline Other axis I disorder & 2 & 1 & Fisher's NS \\
\hline $\begin{array}{l}\text { Any personality } \\
\text { disorder }\end{array}$ & 15 & 5 & $\begin{array}{l}\text { Fisher's } \\
\mathrm{P}<0.01\end{array}$ \\
\hline $\begin{array}{l}\text { Histrionic personality } \\
\text { disorder }\end{array}$ & 5 & 0 & - \\
\hline HRDS (mean score) & 10.7 & 4.1 & $\begin{array}{l}t=5.2 \\
\mathrm{P}<0.001\end{array}$ \\
\hline GAF (mean score) & 67.1 & 80.4 & $\begin{array}{l}t=3.24 \\
\mathrm{P}<0.01\end{array}$ \\
\hline
\end{tabular}

HRDS=Hamilton rating depression scale; $\mathrm{GAF}=$ global assessment of functioning score.

with four controls (Fisher's, $\mathrm{P}<0.001$ ) and more conversion patients had at some stage in their lives consulted a psychiatrist: 14 versus three among controls (Fisher's, $\mathrm{P}<0.01$ ). Six of the patients in the conversion group had earlier in their lives been diagnosed as having a conversion symptom whereas this was not the case in any of the controls.

A significantly higher number of patients in the conversion group had concomitant DSM III-R psychiatric syndromes according to axis I and II (table 3) and HRDS scores were also significantly higher.

Complaints of benign pain - that is, tension type headache and lower back pain-were registered significantly more often among conversion patients compared with controls (table 3) and the global assessment of functioning score was significantly lower in conversion patients than in controls. Concomitant somatic disease was also seen more often in the conversion group, but the difference did not quite reach significance. Of the 10 patients in the conversion group with somatic illness, two patients had diabetes, two had a significant lumbar discus prolapse, and the remaining six patients had colitis ulcerosa, rheumatoid arthritis, hypertension, amaurosis, asthma, and gastritis. Asthma, hypothyreosis, cardiomyopathy, and gastritis were registered in four patients in the control group.

The mean number of life events three months before symptom onset was 1.40 in the conversion group and 0.37 among controls $(t$ test; $t=5.6 ; \mathrm{P}<0.01)$ and for life events one year before symptoms the corresponding figures were 2.70 and 1.67 ( $t$ test; $t=4.3 ; \mathrm{P}<0.01$ ). There were no significant sex differences in either of the groups and no significant differences when assessing patients with and without personality disorders separately. The figure shows the further characteristics of life events experienced among conversion patients and controls.

A logistic regression analysis was performed among all patients with motor disability with conversion as dependent variable and sex, schooling (primary, high or university), presence of personality disorder, and high Hamilton score (upper quartile) as independent variables. The overall prediction was $78.33 \%$ correct in the model. The adjusted odds ratio 


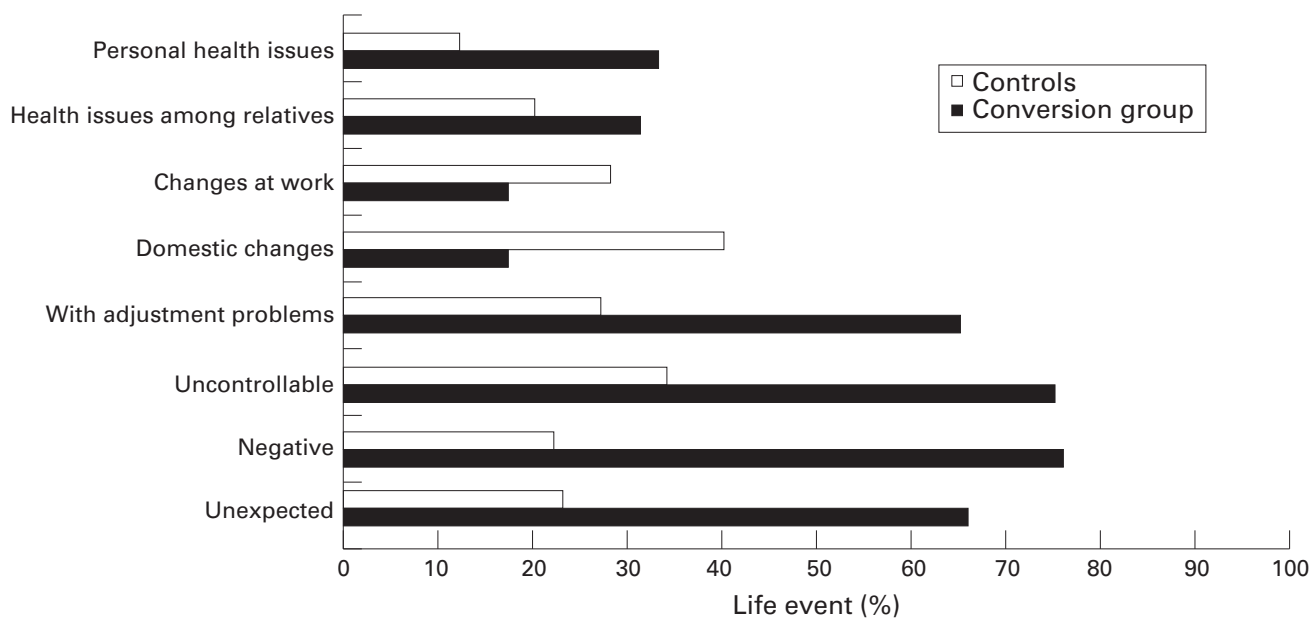

Type of life event preceding symptom onset (proportion of life events in each group)

for poor schooling was 9.62 (95\% confidence interval (95\% CI) 3.28-28.18), presence of a personality disorder 3.05 (95\% CI 1.37-6.80), and high Hamilton score 3.31 (95\% CI $1.24-8.82)$. Sex was not a significant variable in the model.

\section{Discussion}

One of the problems in diagnosing conversion disorder is the assessment of psychological factors and whether or not they should be associated with the conversion symptom. We have tried to minimise the obvious risk of observer bias by quantifying the amount of emotional stress using a semistructured life event inventory. Another problem is the risk of including patients with occult somatic disease as has been shown in several earlier studies. ${ }^{17} 19212728$ This risk was also minimised by choosing patients with motor symptoms, in whom a thorough clinical investigation is usually enough to exclude somatic pathology. This resulted in a very homogeneous group, but also excluded a large proportion of patients with non-organic symptoms in neurological practice-namely, patients with concomitant neurological disease.

The two centres participating in the study produced very similar incidences. If we accept that between a third and half of the patients with conversion manifest motor symptoms as suggested in many previous studies, ${ }^{12} 1821$ the figures compare well with the study of Stefansson et al who found that the total incidence of conversion disorder was around 15/100 000 in Iceland and 22/100 000 in New York. ${ }^{17}$ Our results could represent a minimum partly because of our severe inclusion criteria, and partly because we did not account for patients with mild disability who were not in need of admission to hospital or who may not even have been referred to us. Marsden ${ }^{29}$ and Lewis and Berman $^{30}$ found that about $1 \%$ of all admissions to a neurological ward are made up of patients with conversion disorder which would be somewhat lower than in the present study if we adjust for conversion symptoms other than motor symptoms. A German study ${ }^{12}$ presented a figure as high as $9 \%$ and a
Sudanese study $7.4 \%,{ }^{28}$ but both of these studies also included patients with pain and probably reflect different referral patterns as well as differences in data acquisition and interpretation.

Earlier studies ${ }^{12} 1317$ 29-33 leave no doubt about the female preponderance in conversion syndromes, and the present study confirms this. The mean age of the patients was somewhat higher than in most other studies, ${ }^{12} 1317$ which may be due to the fact that six of the patients had had conversion symptoms previously in their lives, but it could also be that patients with motor conversion represent a subgroup with a later age of onset of symptoms. We found no age difference between the sexes as some previous studies have indicated, in which the highest risk for women seems to be in the second and third decade whereas men seem to peak in the fifth decade. $^{1012171820}$ As in this study, there is earlier evidence that patients are more apt to be the youngest child in the family, ${ }^{15}{ }^{16}$ although other studies show no relation with birth position..$^{2034}$

Most studies show that conversion symptoms are seen more often in poorly educated people of low socioeconomic status, ${ }^{17} 1834$ and the present study confirms this impression although the $95 \%$ CI for poor schooling was very wide, with an adjusted odds ratio of 9.6. In less educated patients the available means of coping with precipitating life events may be more limited. In these patients, sickness might become the most feasible way of gaining relief from emotional strain, the symptom thus taking on an effective protective function.

Notable in the clinical presentation is the fact that as many as $30 \%$ present with monoparesis, which is rare among patients with pareses due to organic causes. The high proportion of patients with left sided symptoms seen in this study has been noted in earlier studies, ${ }^{3637}$ and it has been proposed that unconscious processes could be mediated by the right hemisphere operating independently of the left hemisphere. ${ }^{36}$ In this context it is interesting that hemi-inattentiveness is also associated with the non-dominant hemisphere. 
An alternative explanation is that patients unconsciously select the left side for reasons of convenience because it is less incapacitating for daily activities.

The frequent association of conversion symptoms with organic disease has been noted for over 100 years and most studies show a high percentage of coexisting or antecedent organic disorder. ${ }^{511} 1721{ }^{38}$ Even though in this study we specifically excluded patients with neurological disease, a third of the conversion patients were found to have a significant concomitant somatic disease. Significantly more complaints of diffuse, non-organic pain were registered in the index group, and as many as $21(70 \%)$ of the patients had a history of previous somatic ailments requiring inpatient hospital assessment.

The high incidence of depression in the conversion patients compared with controls is confirmed by most other studies, ${ }^{512} 13172139$ all showing a high percentage of affective disorder, which obviously has important conceptual and therapeutic implications. There was also a high degree of previous psychiatric morbidity, in which $47 \%$ of patients at some stage of their lives had been in contact with a psychiatrist for various reasons. As many as half of the conversion patients were shown to have personality disorders according to the SCID interview. This is somewhat higher than in most other studies, in which the frequency of personality disorders is in the range of $16 \%-46 \% .{ }^{13} 19203440$ Reasons for this could be the strict inclusion criteria in this study or the use of the SCID interview as a diagnostic instrument, but the motor group might also represent a subgroup with a higher comorbidity on the DSM-IV axis II. Seventeen per cent had histrionic personality disorder, a figure that compares well with previous studies showing between $7 \%$ and $34 \%, 1217202132343539$ and indicating that a subgroup seems to display hysterical traits. Histrionic personality may thus be a predisposing factor, although on the whole patients with conversion seem to have heterogeneous personality styles, and of the remaining 10 patients with personality disorders six different disorders were represented, whereas half of the patients in this study had a completely normal personality. The personality characteristics do, however, differ significantly from the controls, emphasising a definite contribution of personality to the pathogenesis and presentation of conversion phenomena.

An interesting finding was the fact that an extremely high proportion of conversion patients had near relatives with psychiatric disease or severe somatic disease, although information was not based on hospital records, and thus could be subject to patient bias. The conversion symptom in some cases could be a consequence of inappropriate coping with the emotional stress that is associated with severe illness in a near relative, and might represent an appeal for support from the surroundings. Looking back on the year before symptom onset, conversion patients clearly perceived more difficulties in global functioning compared with control patients. This might well be due to the higher number of life events experienced. These life events were mostly perceived as negative, difficult to adjust to, and on the whole mostly uncontrollable. Even though the precipitation of organic disease by stressful life events is well known, significantly fewer life events were registered in the neurological control group. Obviously there can be great difficulty in judging the importance of a potential stress factor, and we are aware of the pitfalls which can arise from extrapolation of the results from life event schedules. Our findings should therefore be treated cautiously, even though each item in the life event inventory is defined as specifically as possible to minimise ambiguous interpretation. Other studies ${ }^{18} 21$ seem to confirm the presence of significant emotional stress before the onset of conversion symptoms. It may be assumed that the perception of and the reaction to external stressful events are modulated by the personality structure of the person experiencing the event, and in this study patients with personality disorders experienced a somewhat higher mean number of life events compared with patients with a normal personality $(2.8 v 2.0)$ but this difference did not reach significance.

In summary the importance of several previously reported predisposing and precipitating factors can be confirmed, with recent life events, low education, and high Hamilton psychiatric rating depression scale score having the highest bearings. We also found a high proportion of antecedent and concurrent organic as well as psychiatric comorbidity. There was only one patient without any signs of previous or present illness compared with 17 patients in the neurological control group. The study thus supports the notion that conversion should be treated as a symptom rather than a diagnosis and that efforts should be made in diagnosing and treating possible underlying somatic or psychiatric conditions. The large proportion of negative life events and personality disorders in this study support the speculation of Merskey and Buhrich that the importance of emotional conflict and personality type might be greater in conversion patients without cerebral disorders, contrary to patients with well established neurological disease who may not need these additional precipitating factors to the same extent. ${ }^{41}$

The neurologist who encounters patients with psychogenic paralysis probably will not have diagnostic difficulties, but he should look for occult and psychiatric comorbidity. Apart from exploring the possibility of organic disease, the risk of personality disorders should be considered. Attention should also be paid to trying to identify negative life events that could be associated with the patient's symptom. Clinical experience suggests that the patient's understanding of such a link usually is an advantage in treatment. An exciting prospect for future research would be to elucidate which of the features associated with motor conversion have a bearing on clinical outcome. 
1 American Psychiatric Association. Diagnostic and statistical manual of mental disorders, 4th ed. Washington DC: APA, manual

2 Ford CV, Folks DG. Conversion disorders: an overview. Psychosomatics 1985;26:371-83.

3 Hollender MH. Conversion hysteria (a post-Freudian reinterpretation of 19th century psychosocial data). Arch Gen Psychiatry 1972;26:311-4.

4 Mace CJ. Hysterical conversion II: a critique. Br F Psychiatry 1992;161:378-89.

5 Marsden CS. Hysteria-a neurologist's view. Psychol Med 1986;16:277-88.

6 Merskey H. Conversion symptoms revised. Semin Neurol 1990;10:221-8.

7 Binzer M, Kullgren G. Conversion symptoms - what can we learn from previous studies? Nord f Psychiatry 1996;50: 143-52.

8 Coryell W, House D. The validity of broadly defined hysteria and DSM-III conversion disorder: outcome, family history, and mortality. $\mathcal{F}$ Clin Psychiatry 1984;45:252-6.

9 tory, and mortality. $\mathcal{F}$ Clin Psychiatry $1984 ; 45: 252-6$. version symptoms. Br f Psychiatry 1968;114:1121-5.

10 Guze SB, Woodruff RA, Clayton PJ. A study of conversion symptoms in psychiatric outpatients. Am $\mathcal{F}$ Psychiatry

11 Hafeiz HB. Hysterical conversion: a prognostic study. $\mathrm{Br} F$ Psychiatry 1980;136:548-51.

12 Lempert T, Dietrich M, Huppert D, Brandt T. Psychogenic disorders in neurology: frequency and clinical spectrum. Acta Neurol Scand 1990;82:335-40.

13 McKegney PF. The incidence of characteristics of patients with conversion reactions. Am f Psychiatry 1967;124:5425 .

14 Dilling $\mathrm{H}$, Mombour W, Schmidt $\mathrm{MH}$. International Classification of Psychiatric Disorders: ICD-10, chapter V, clinical diagnostic guidelines. Toronto: World Health Organisation, 1991 .

15 Ziegler FJ, Imboden JB, Meyer E. Contemporary conversion reactions: a clinical study. Am $\mathcal{F}$ Psychiatry 1960;116: sion reactio.

16 Stephens JH, Kamp M. On some aspects of hysteria: a clinical study. F Nerv Ment Dis 1962;134:305-15.

17 Stefansson JG, Messina JA, Meyerowitz S. Hysterical neurosis, conversion type: clinical and epidemiological considerations. Acta Psychiatr Scand 1976;53:119-38.

18 Maxion H, Fegers S, Pfluger R, Wiegand J. Risikofaktoren klassischer Konversionssyndrome - psychogene Anfälle und Paresen - Beobachtungen einer neurologischen Klinik bei 172 Patienten. Psychtherapie und Medizinische Psychologie 1989;39:121-6.

19 Folks DG, Ford CV, Regan WM. Conversion symptoms in a general hospital. Psychosomatics 1984;25:285-9.

20 Ljungberg L. Hysteria: a clinical, prognostic and genetic study. Acta Psychiatr Neurol Scand 1957;112(suppl):1-62.
21 RaskinM, Talbott JA, Meyerson AT. Diagnosed conversion reactions: predictive value of psychiatric criteria. $\mathcal{f} A M A$ 1966;197:530-4.

22 Spitzer RL, Williams JBW, Gibbon M. Structured clinical interview for DSM-III-R. Biometrics Research. New York: New York State Psychiatric Institute, 1987

23 Spitzer RL, Williams JBW, Gibbon M, First MB. The structured clinical interview for DSM-III-R (SCID). 1. History, rationale and description. Arch Gen Psychiatry 1992:49; $624-9$.

24 Bodlund O, Kullgren G, Ekselius L, Lindstrom E, von Knorring L. Axis V - Global assessment of functioning scale. Evaluation of a self-report version. Acta Psychchiatr Scand 1993;88:322-7.

25 Hamilton MA. A rating scale for depression. 7 Neurol Neurosurg Psychiatry. 1960;23:56-62.

26 Perris H. Life events and depression. I. effect of age, sex and civil status. F Affect Disord 1984:7;11-24.

27 Lempert T, Dietrich M, Huppert D, Brandt T. Psychogenic Lempert T, Dietrich $M$, Huppert $\mathrm{D}$, Brandt T. Psychogenic
disorders in neurology: frequency and clinical spectrum. disorders in neurology: frequency
Acta Neurol Scand 1990;82:335-40.

28 Hafeiz HB. Hysterical conversion: a prognostic study. $\mathrm{Br} \mathcal{F}$ Hafeiz HB. Hysterical conver

29 Marsden CS. Hysteria - a neurologist's view. Psychol Med 1986; 16:277-88.

30 Lewis WC, Berman M. Studies of conversion hysteria. Arch Gen Psychiatry 1965;13:275-82

31 Purtell JJ, Robins E, Cohen ME. Observations on clinical aspects of hysteria. A quantitative study of 50 hysteria patients and 156 control subjects. FAMA 1951;146:902-9.

32 Merskey H, Trimble M. Personality, sexual adjustment, and brain lesions in patients with conversion symptoms. Am $\mathcal{F}$ Psychiatry 1979;136:179-82.

33 Roy A. Hysteria. J Psychosom Res 1980;24:53-6.

34 Barnert C. Conversion reactions and psychophysiologic disorders: a comparative study. Psychiatr Med 1971;2: 205-20.

35 Wilson-Barnett J. Trimble MR. An investigation of hysteria using the illness behaviour questionnaire. Br $\mathcal{F}$ Psychiatry 1985;146:601-8.

36 Stern DB. Handedness and the lateral distribution of conversion reactions. F Nerv Ment Dis 1977;164:122-8.

37 Galin D, Diamond R, Braff D. Lateralization of conversion symptoms: more frequent on the left. Am $\mathcal{F}$ Psychiatry 1977:134:578-80.

38 Whitlock FA. The aetiology of Hysteria. Acta Psychiatr Scand 1967;43:144-62.

39 Chodoff $\mathrm{P}$, Lyons H. Hysteria, the hysterical personality and "hysterical" conversion. Am F Psychiatry 1958;114:734-40.

40 Lecompte D, Clara A. Associated psychopathology in conversion patients without organic disease. Acta Psychiatr Belg 1987;87:654-61.

41 Merskey $\mathrm{H}$, Buhrich NA. Hysteria and organic brain disease. Br f Med Psychol 1975;48:359-66. 